\title{
Income-related inequalities in health: some international comparisons
}

\author{
Eddy van Doorslaer ${ }^{a}$, Adam Wagstaff ${ }^{\text {b. }}$, Han Bleichrodt ${ }^{a}$, \\ Samuel Calonge ${ }^{c}$, Ulf-G. Gerdtham ${ }^{d}$, Michael Gerfin ${ }^{c}$, \\ José Geurts ' , Lorna Gross ${ }^{\text {g }}$, Unto Häkkinen ' \\ Robert E. Leu ${ }^{\mathrm{e}}$, Owen O'Donnell i, Carol Propper ', \\ Frank Puffer ${ }^{\text {k }}$, Marisol Rodríguez c , Gun Sundberg ', \\ Olaf Winkelhake $^{\mathrm{m}}$ \\ a Deparment of Health Policy and Management, Erasimus Unicersity. 3000 DR Rotterdam, \\ Netherlands \\ 'School of Social Sciences. Unicersity of Sussex, Brigh:on BNI 9QN, UK \\ 'Deparment of Economic Policy. Unicersity of Barcelona, 08034 Barcelona, Spain \\ 'Centre for Health Economics. Stockholm School of Economics, II383 Stockholm, Sweden \\ 'Department of Economics, Unicersity of Bern. 3012 Bern. Switzerland \\ 'Statistics Netherlands, 640I CZ Heerlen. Netherlands \\ 'Department of Economics. Worcester State College, Worcester MA. USA \\ t National Research and Decelopment Centre for Welfare and Health, 00531 Helsinki, Finland \\ 'Deparment of Economics, Unitersity of Kent. Canserbuny CT2 TPN, UK \\ 'Deparment of Economics, Unitersity of Bristol, Bristol BS8 ITH, UK \\ ${ }^{k}$ Department of Economics, Clark Unicersity, Worcester, MA OI610. USA \\ 'Department of Economics, Uppsala Unicersity. 75120 Uppsala. Sweden \\ "GSF-Medis, 8575 Oberschleissheim, Germany
}

Received 1 May 1995; revised I May 1996

\begin{abstract}
This paper presents evidence on income-related inequalities in self-assessed health in nine industrialized countries. Health interview survey data were used to construct concentration curves of self-assessed health, measured as a latent variable. Inequalities in health
\end{abstract}

\footnotetext{
Corresponding author. Tel.: 441273 606755: Fax.: 44 1273 673563; E-mail: a.wagstaff@sussex.ac.uk.
} 
favoured the higher income groups and were statistically significant in all countries. Inequalities were particularly high in the United States and the United Kingdom. Amongst other European countries, Sweden. Finland and the former East Germany had the lowest inequality. Across countries, a strong association was found between inequalities in health and inequalities in income. 1997 Elsevier Science B.V. All rights reserved.

JEL classification: D30: D31: I10; 112

Kevwords: Health inequality: International comparisons

\section{Introduction}

The issue of whether socioeconomic inequalities in health are more pronounced in some countries than in others is clearly an important one, not least because it may shed light on the causes of inequalities in health. Despite this, there is surprisingly little empirical evicience on the subject. Many of the multi-country studies to date have either avoided making comparisons between countries (cf. Blaxter, 1989) - a stance we believe to be unnecessarily extreme - or have been confined to only a few countries at a time (cf. Lundberg, 1986; Vågerö and Lundberg, 1989; Lahelma and Valkonen. 1990). Exceptions are the papers by Le Grand (1987, Le Grand, 1989), Kunst and Mackenbach (1992, Kunst and Mackenbach, 1994a) and Valkonen (1989) on inequalities in mortality, and the papers by Kunst et al. (1992. Kunst et al., 1995) on inequalities in morbidity.

This paper provides additional evidence on the extent of international differences in inequalities in morbidity. It differs from previous work in the field in a number of respects. First. we stratify our samples by income. Our work thus differs from that of Le Grand $(1987,1989)$, who did not stratify and investigated pure inequalities in health, and complements that of the other aforementioned studies, which have either stratified by educational attainment or by occupation. ' Secondly, we have confined our cross-country comparisons to self-assessed health. This has the attraction of being widely available and the questions vary only marginally across surveys. Other indicators, such as bed-ridden days and long-term disability, are less readily available, whilst indicators such as the presence or absence of chronic illness, although fairly widely available, vary considerably across surveys. 2 Self-assessed health differs, of course. from many of these other indicators in that it does not rely on a medical conceptualization of health and it

\footnotetext{
'Some previous studies have also used income as a stratifying variable but have included only a few countries at a time - see Section 5 below.

2 Sarveys differ in the wording of the question (for example. in some countries disabilities are picked up in the question. whilst in others they are not). in the way the question is posed (in some cotantries a checklist is used. which seems to increase the likelihood of people reporting a chronic condision). and in the range of conditions covered in the question (where checklists are used. they are sometimes confined to a limited number of conditions).
} 
uses respondents' own assessments of their health. Many find this attractive, though there may well be those who would prefer a more objective measure of health. Thirdly, in our treatment of the self-assessed health indicator, we have avoided dichotomizing the variable - an approach that can lead to different results depending on where the cut-off point is set. Instead, we have assumed that underlying the responses to the question concerning self-assessed health is a continuous latent variable. Fourthly, in contrast to several of the measures of inequality used in the literature on inequalities in health, our measure - the concentration index - satisfies three basic requirements of an index of inequality in health. This is related to the relative index of inequality (cf. Pamuk, 1985), but has, in our view, rather more visual appeal, being derived from concentration curves. Furthermore, it has a firm grounding in the literature on income distribution and redistribution - its properties and the value judgements underlying it are therefore reasonably well understood. ${ }^{3}$ Finally, in contrast to many studies in this area, the present paper reports standard errors for the inequality index used, thus allowing statistical tests to be performed of cross-country differences in inequality. Our standard error estimators, unlike those used in the few studies of inequalities in health to date that have reported standard errors, take into account the serial correlation that inevitably arises when a ranking variable is used.

\section{Methods}

A variety of measures of inequality have been employed in the literature on inequalities in heaith. However, only two of these satisfy the three basic requirements of an index of inequality in health: (i) that it reflects the sccioeconomic dimension to inequalities in health; (ii) that it reflects the experiences of the entire population; and (iii) that it is sensitive to changes in the distribution of the population across socioeconomic groups. ${ }^{4} \mathrm{~A}$ surprising number of the indices used fail to satisfy the first of these requirements, being unable to distinguish between a situation where the sickest members of society are millionaires and one where they are the very poor. These include the Gini coefficient (cf. Illsley and Le Grand, 1987; Le Grand and Rabin, 1986; Le Grand, 1987, 1989), the index of dissimilarity (cf. Koskinen, 1985; Preston et al.. 1981) and the index of inequality used by Pappas et al. (1993). One measure which does pass this test is the range, but this fails on the second and third two criteria, focusing, as it does, on the experiences of the extreme groups and failing to reflect the distribution of the population across the various groups. The only two indices to satisfy all three

\footnotetext{
${ }^{3}$ See, for example, Kakwani (1977. Kakwani. 1980) and Lambert (1993).

4 For a survey of these indices and the extent to which they met the three minimal requirements. see Wagstaff et al. (1991).
} 


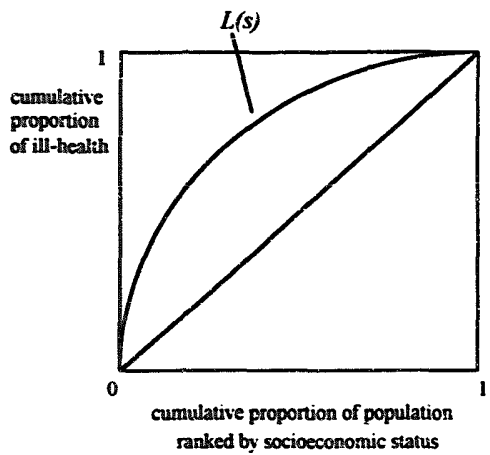

Fig. I. Illness concentration curve.

criteria are the relative index of inequality (cf. Preston et al., 1981; Pamuk, 1985 , 1988) and the concentration index (cf. Wagstaff et al., 1989). Since these two measures are related to one another ${ }^{5}$ and since the concentration index has, in our view, a more immediate visual appeal, this is the measure of inequality used in this paper.

Suppose we have a continuous measure of ill-health. The concentration curve $L(s)$ in Fig. I plots the cumulative proportion of the population (ranked by socioeconomic status, beginning with the least advantaged) against the cumulative proportion of ill-health. If $L(s)$ coincides with the diagonal, then everyone enjoys the same health. If, by contrast, $L(s)$ lies above (below) the diagonal, then inequalities in ill-health exist and favour the more (less) advantaged members of society. The farther $L(s)$ lies from the diagonal, the greater the degree of inequality. If $L(s)$ of country $X$ is everywhere closer to the diagonal than that of country $Y$, then country $X$ 's concentration curve is said to dominate that of country $Y$. It seems reasonable in such cases to conclude that there is unambiguously less inequality in ill-health in country $X$ than in country $Y .^{6}$ Where concentration carves cross, or where, in any case, we want a numerical measure of health inequality, we can use the ill-health concentration index, $C$, defined as

\footnotetext{
5 The relative index of inequality is equal to the concentration index divided by a number that approaches a constam as the sample size grows. See Wagstaff et al. (1991) and Kakwani et al. (1997). and the discussion below.

${ }^{6}$ We conjecture that it would be possible to prove an analogue of the theorem of Atkinson (1970) for the case of health inequality, the difference being of course that the ranking variable in this case is not tealth but rather socioeconomic status. This aversion to socioeconomic inequality would need taking into atcount in the social welfare function.
} 
twice the area between $L(s)$ and the diagonal. $C$ takes a value of zero when $L(s)$ coincides with the diagonal and is negative (positive) when $L(s)$ lies above (below) the diagonal. The minimum and maximum values of $C$ using individuallevel data are -1 and +1 , respectively: these occur when all the population's ili-iealth is concentrated in the hands of the most and least disadvantaged persons, respectively.

Comparing $L(s)$ with the diagonal measures all socioeconomic inequalities in health, without correcting for any confounding effects. It is well known that both health and income are associated with exogenous demographic factors, such as age and gender, and that failure to take these into account might lead to an overestimation of the extent of socioeconomic inequalities in health (cf. Kunst and Mackenbach, 1994b). One way to correct for differences in demographic factors is to employ the direct method of standardization. This requires that persons be grouped into socioeconomic groups (SEGs) and involves applying the age-sex-specific average rates of ill-health of each SEG to the age and gender structure of the population. The standardized rate of ill-health for SEG $t$ is equal to

$$
\mu_{t}^{+}=\sum_{d} n_{d} \mu_{d l} / n,
$$

where $n_{d}$ is the number of persons in the $d$ th demographic group in the population as a whole, $\mu_{d t}$ is the morbidity rate amongst persons in the $d$ th demographic group in SEG $t$, and $n$ is the number of persons in the sample. From these, we can compute the share of standardized ill-health accounted for by each SEG. Let $L^{+}(s)$ be the concentration curve derived from these shares. If $L^{+}(s)$ lies above the diagonal, then the less advantaged SEGs experience higher age-sex-specific rates of ill-health than the population as a whole, whilst the opposite is true if $L^{+}(s)$ lies below the diagonal. A measure of inequalities in health unrelated to different age and gender compositions of the socioeconomic groups is thus the (age-sex) standardized concentration index, $\mathrm{C}^{+}$, defined as twice the area between $L^{+}(s)$ and the diagonal. This is negative (positive) if avoidable inequalities favour the more (less) advantaged SEGs and zero if there are no avoidable inequalities in health.

If $\mathrm{L}^{+}(s)$ is assumed to be piecewise linear, then $\mathrm{C}^{+}$can be calculated as (cf. Kakwani et al., 1997)

$$
C^{+}=\frac{2}{\mu^{+}} \sum_{t=1}^{T} f_{t} \mu_{t}^{+} R_{t}-1,
$$

where $\mu^{+}=\sum_{i=1}^{T} f_{t} \mu_{\varepsilon}^{+}$is the mean standardized rate of ill-health of the sample, $f_{t}$ is the proportion of the sample in SEG $t$, and $R_{t}$ is the relative rank of the $t$ th SEG. The latter is defined as

$$
R_{t}=\sum_{\gamma=1}^{t-1} f_{\gamma}+\frac{1}{2} f_{t},
$$


and thus indicates the cumulative proportion of the population up to the midpoint of each group interval. As Kakwani et al. (1997) show, $C^{+}$can alternatively be calculated by means of the following convenient regression:

$$
2 \sigma_{R}^{2}\left[\mu_{t}^{+} / \mu^{+}\right] \sqrt{n_{t}}=\alpha_{1} \cdot \sqrt{n_{t}}+\beta_{1} \cdot R_{t} \sqrt{n_{t}}+u_{t},
$$

where $\sigma_{R}^{2}=\sum_{t=1}^{T} f_{t}\left(R_{t}-(1 / 2)\right)^{2}$ is the variance of $R_{t}$ and $\mu^{+}$is the mean of the standardized rate of ill-health. The estimator of $\beta$ is equal to

$$
\hat{\boldsymbol{\beta}}=\frac{2}{\mu_{i=1}} \sum_{i=1}^{T} f_{t}\left(\mu_{t}^{+}-\mu^{+}\right)\left(R_{t}-\frac{1}{2}\right)
$$

which, given that the mean of $R_{t}$ is equal to one-haif, gives the result

$$
\hat{\boldsymbol{\beta}}=\boldsymbol{C}^{+} \text {. }
$$

As Kakwani et al. note, the parallel with the relative index of inequality is clear from $\mathrm{Eq}$. (4), the relative index of inequality being equal to the slope coefficient in a weighted least squares regression of a group's relative ill-health on its relative rank:

$$
\left[\mu_{t}^{+} / \mu^{+}\right] \sqrt{n_{t}}=\alpha_{1} \cdot \sqrt{n_{t}}+\beta_{1} \cdot R_{t} \overline{n_{t}}+u_{t},
$$

where $\beta_{1}$ is the relative index of inequality. From the above, it follows that

$$
\hat{\beta}_{1}=\frac{C^{+}}{2 \sigma_{R}^{2}} \text {. }
$$

Hence our earlier claim that the concentration index and relative index of inequality are related.

Although standard errors for $\mathrm{C}^{+}$(and, for that matter, the relative index of inequality) can be obtained from Eq. (4) (Eq. (7) in the case of the relative index of inequality), these are inaccurate, since the presence of the relative rank variable on the right-hand side of Eqs. (4) and (7) means that the observations in the regression equation are not independent of one another and hence the errors are subject to autocorrelation. ${ }^{7}$ Kakwani et al. develop an accurate estimator for the standard error of $\mathrm{C}^{+}$(and the relative index of inequality) that takes this into account. It is this estimator that we use in the present paper.

\footnotetext{
${ }^{7}$ The standard errors for the relative index of inequality reponed by Kunst and Mackenbach (1992. Kunst and Mackenbach. 1998a) and Kunst et al. (1992. Kunst et al., 1995) are based on these regression-bassed estimators and are hence potentially misleading. A priori it is not possible to predict the size of any inaccuracies resulting from the use of this estimator. Nor indeed is it possible to say a priori whether the confidence intervals are likely to be unduly small or unduly large. Results reported in Kakwani et al. (1997) suggest that in the case of the Netherlands the inaccuracies may not be that large. but whether this is true of other samples too remains to be seen.
} 


\section{Data and variable definitions}

The surveys used are listed in Table $1 .{ }^{8}$ The sample used comprises all adults, except in the Swedish case where the sample comprises all adults aged 75 or less. Sample sizes vary substantially, from Sweden's 3300 to the United States's 22,000 . Some samples exclude the institutionalized population. All of the surveys refer to the 1980s, except those for Sweden (1991) and Germany (1992). Because the German survey was done so soon after unification, we have treated the former East Germany and the former West Germany as two countries.

Our measure of socioeconomic status (i.e. our ranking variable) is disposable (i.e. after-tax) household income per equivalent adult, grouped into deciles for the direct standardization. Most of the surveys used contain good information on income - this reflects in part the fact that most are not health surveys but rather multi-purpose surveys. The Dutch and U.S. surveys, despite being health surveys, have good data on income, with respondents being asked to provide the exact amount of their household's income as well as details of income sources. ${ }^{9}$ The Spanish survey, which is a health interview survey, has slightly less detailed information on income, respondents there being asked simply to indicate in which of several classes their household's income fell - in this case, the household income of each individual was calculated as the midpoint of their household income class. Different equivalence scales were used in each country, the choice being dictated by previous research in the country in question. Whether we should use different scales in a study of this type is a moot point. On the one hand, using different equivalence scales allows for possible differences between countries in household production economies of scale and variations in expenditure needs between persons of different ages (e.g. owing to differences between countries in their VAT rating of children's clothes). ${ }^{10}$ On the other hand, the use of different scales risks inviting the response that any inter-country differences emerging simply reflect the equivalence scale differences (cf. O'Higgins et al., 1990, p.25).

\footnotetext{
${ }^{8}$ There are, in fact. 15 countries participating in the ECuity project. However, not all were able to produce comparable results to those produced by the countries listed in Table 1. Some (e.g. France. Ireland and Portugal) did not at the time have access to survey containing a self-assessed health variable. In other cases. data on equivalent income were not comparable. sometimes because no data on income were available in the health interview survey (e.g. one of the available ftalian surveys), sometimes because the income variable referred to pre-tax income rather than disposable income (e.g. Denmark). and sometimes because data on household structure were absent from the survey thereby preventing equivalization (e.g. the other principal Italian survey).

${ }^{9}$ In the Dutch survev, households unable or unwilling to state the exact amount of income were asked to assign themselves to an income class.

${ }^{10}$ While a case can be made for using different scales in different countries, it seems highly desirable that the scales be derived using the same econometric mocel. Regrettably this is not true of the scales used in the present study.
} 
Table 1

Details of surveys

\begin{tabular}{|c|c|c|c|c|c|}
\hline$\overline{\text { Cousatry }}$ & $\begin{array}{l}\text { Abtreviation } \\
\text { of cosntry } \\
\text { name }\end{array}$ & Year & Survey & $N$ & $\begin{array}{l}\text { Institution- } \\
\text { alized } \\
\text { population } \\
\text { excluded? }\end{array}$ \\
\hline Finland & SF & 1987 & $\begin{array}{l}\text { Health and Social Security } \\
\text { Survey }\end{array}$ & 11.956 & Yes \\
\hline West Gemany & WG & 1992 & Socio Economic Panel Survey & 6425 & Yes \\
\hline East Germany & EG & 1992 & Socio Economic Panel Surrey & 3890 & Yes \\
\hline The Netherlands & $\overrightarrow{\mathrm{NL}}$ & $1986-88$ & Health Interview Survey & 15,457 & Yes \\
\hline Spain & $\mathbf{E}$ & 1987 & Health Interview Survey & 17.419 & Yes \\
\hline Sweder ${ }^{3}$ & $\mathbf{S}$ & 1990 & LNU Level of Living Survey & 3374 & No \\
\hline Switzerlasd & $\mathrm{CH}$ & 1982 & SOMIPOP Survey & 3790 & No \\
\hline Unized Kingdom & UK & 1985 & General Household Survey & 13,099 & Yes \\
\hline United States & US & 1987 & $\begin{array}{l}\text { National Medical Expenditure } \\
\text { Survey }\end{array}$ & 22,226 & Yes \\
\hline
\end{tabular}

Upper age limit of 76.

Our health indicator is, as indicated in the Introduction, seif-assessed health. The wording of the self-assessed health questions used in the present study, the number of response categories and the labels are indicated in Table 2. One difference in the wording of the question is the reference period: 'the present' in

Table 2

Details of self-assessed health questions

\begin{tabular}{|c|c|c|c|}
\hline Counary & Wording of question & $\begin{array}{l}\text { No. of } \\
\text { response } \\
\text { categories }\end{array}$ & Response categories \\
\hline Finland & $\begin{array}{l}\text { How good do you consider your } \\
\text { present state of health to be? }\end{array}$ & 5 & $\begin{array}{l}\text { Good. fairly good. average. } \\
\text { rather poor, poor }\end{array}$ \\
\hline Germany & $\begin{array}{l}\text { How would you describe your } \\
\text { current health status? }\end{array}$ & 5 & $\begin{array}{l}\text { Very good. good. satisfactory. } \\
\text { less good. poor }\end{array}$ \\
\hline Netberlands & How is your health in general? & 5 & $\begin{array}{l}\text { Very good. good. fair. sometimes } \\
\text { good and sometimes bad. bad }\end{array}$ \\
\hline Spain & $\begin{array}{l}\text { During the past } 12 \text { months. } \\
\text { how would you say your } \\
\text { health has been? }\end{array}$ & 4 & $\begin{array}{l}\text { Very good. good. fair. } \\
\text { poor / very poor a }\end{array}$ \\
\hline Sweden & $\begin{array}{l}\text { How do you judge your general } \\
\text { health status? }\end{array}$ & 3 & Good, between good and bad. bad \\
\hline Switzerland & How is your health? & 4 & Excellent. good, not so good, poor \\
\hline United Kingdon & $\begin{array}{l}\text { Over the last } 12 \text { months. } \\
\text { how would you say your } \\
\text { health has been on the whole? }\end{array}$ & 3 & Good. fairly good. not gocd \\
\hline United States & $\begin{array}{l}\text { How would you say your health } \\
\text { status is in general? }\end{array}$ & 4 & Excellent, good, fair, poor \\
\hline
\end{tabular}

The botton two categories (poor and very poor) have been combined in the analysis. 
the cases of Finland and Germany; 'the last 12 months' in the cases of Spain and the United Kingdom; and no specified period in the remaining four countries. This may well affect our results, though it is unclear in which direction - of the six country reports in van Doorslaer et al. (1993) reporting distributions of chronic illness and acute illness, three found the former less equal than the latter, while the other three found the opposite. The number of response categories offered also differs, varying between three (Sweden and the United Kingdom), four (Spain, Switzerland and the United States) or five (Finland, Germany and the Netherlands),

Typically, research using a self-assessed health variable proceeds by converting the multiple-category self-assessed health variable into a dichotomous variable by dividing the sample into those whose health is, say, at least good, and the rest, by choosing some arbitrary cut-off point. "This is unreliable and can lead to different conclusions concerning trends in or differences in inequalities in health, depending on where the cut-off point is chosen. ${ }^{12}$ Instead, we have assumed here that underlying the responses in each survey is a latent self-assessed health variable with a standard lognormal distribution (cf. Wagstaff and van Doorslaer, 1994). Since our interest lies with relative inequality, the imposition of a common mean is an attractive feature of this approach. The lognormality assumption nas the added attraction of allowing for skewness in the underlying distribution of health. In effect, we obtain the latent health scores for each of the response categories by dividing up the area under the standard logncrmal distribution according to sample proportions falling into each of the response categories. From this we derive a latent health score for each of the response categories. Each person is then assigned the latent health score corresponding to their response. This score is increasing in ill-health, since the best response category is put at the left-hand tail of the distribution. If inequalities favour the less disadvantaged members of society, then the corresponding concentration curve will lie above the diagonal and the concentration index will be negative. To eliminate the confounding effects of demographic variables, we have age-sex standardized our self-assessed health variable using the direct method of standardization. Thus, rather than using the actual sample proportions falling into each response category in each income decile, we have used the demographically expected (i.e. age-sex standardized) proportions. It is these standardized proportions that are then used to construct the latent variable.

\section{Results}

Concentration indices with associated confidence intervals are reported in Table 3. All of the indices are negative and are significantly different from zero,

\footnotetext{
"See, for example. Wagstaff et al. (1989) and Kunst et al. (1992. Kunst et al. 1995).

'2 See Kunst et al. (1992. Kunst et al., 1995) and Wugstaff and van Doorslaer (1993).
} 
Table 3

Heasth concentration indices and confidence intervals

\begin{tabular}{llll}
\hline Country & $\begin{array}{l}\text { Concentration } \\
\text { index }\end{array}$ & $\begin{array}{l}\text { Lower limit of } \\
95 \% \text { confidence interval }\end{array}$ & $\begin{array}{l}\text { Upper limit of } \\
95 \% \text { confidence interval }\end{array}$ \\
\hline Finland & -0.0566 & -0.0815 & -0.0317 \\
East Germany & -0.0436 & -0.0564 & -0.0308 \\
West Germainy & -0.6571 & -0.0831 & -0.0311 \\
The Netheriands & -0.0660 & -0.0964 & -0.0357 \\
Spain & -0.0732 & -0.1019 & -0.0444 \\
Sweder & -0.0347 & -0.0590 & -0.0105 \\
Switzerland & -0.0646 & -0.0882 & -0.0510 \\
Urited Xingdom & -0.1148 & -0.1447 & -0.0849 \\
United States & -0.1360 & -0.1824 & -0.0896 \\
\hline
\end{tabular}

indicating that significant income-related inequalities in health exist in all of these countries and, without exception, favour the higher income groups. There is, however. substantial variation in index values between countries. By far the largest inequality is observed in the United States with a concentration index of -0.14 . Only one other country - the United Kingdorn - has an index smaller than -0.1 . A second cluster of countries is Spain. Switzerland and the Netherlands, with indices of around -0.07 . West Germany and Finland come next, with index values around -0.06 . The countries with the lowest inequality indices are East Germany $(-0.04)$ and Sweden $(-0.03)$, although in the latter case it is worth bearing in mind that the Swedish sample excludes the over-75s amongst whom there might well be a relatively high degree of income-related health inequality.

The question arises of whether the differences in concentration indices reported in Table 3 are statistically significant. Significance tests have been performed using Student's $t$-tests based on the estimated standard errors of the concentration indices. The results of the $t$-tests are reported in the upper triangle of Table 4 . where cruntries have been ranked by their concentration indices. This time. just two ciusters of countries emerge - the first. containing the United States and the United Kingdom. whose concentration indices are significantly larger in absolute value than the indices of the remaining countries, and the second containing the remaining countries, whose concentration indices do not for the most part significantly differ from one another. ${ }^{i,}$

Another way to compare inequalities between countries is by comparing concentration curves. For each of the possible pairwise comparisons we determine whether one country's concentration curve dominates that of the other, strictly

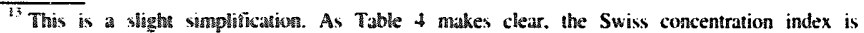
signisicanty differem from the East German and Swedish indices, whilst the Spanish concentration index is not significanty different from that of the United Kingdom.
} 
Table 4

Pairwise comparisons of the nine countries (ranked by concentration index)

\begin{tabular}{|c|c|c|c|c|c|c|c|c|c|}
\hline & Sweden & $\begin{array}{l}\text { East } \\
\text { Germany }\end{array}$ & $\begin{array}{l}\text { Fin- } \\
\text { land }\end{array}$ & $\begin{array}{l}\text { West } \\
\text { Germany }\end{array}$ & $\begin{array}{l}\text { The } \\
\text { Netherlands }\end{array}$ & $\begin{array}{l}\text { Switzer- } \\
\text { land }\end{array}$ & Spain & $\begin{array}{l}\text { United } \\
\text { Kingdom }\end{array}$ & $\begin{array}{l}\text { United } \\
\text { States }\end{array}$ \\
\hline Sweden & - & ns & ns & ns & ns & $\cdot$ & ns & $\cdots$ & $\cdots$ \\
\hline East Germany & $\approx(1)$ & - & ns & as & ns & • & ns & $\cdots$ & $\cdots$ \\
\hline Finland & $\approx(1)$ & $>$ & - & ns & ns & ns & ns & $\cdots$ & $\cdots$ \\
\hline West Germany & $>$ & $>$ & $\approx(1)$ & - & ns & ns & ns & • & $\cdots$ \\
\hline The Netherlands & $>$ & $>$ & $\approx(1)$ & $\approx(1)$ & - & ns & ns & • & $\cdot$ \\
\hline Switzerland & $>$ & $>$ & $=(1)$ & $\Rightarrow(1)$ & $\approx(3)$ & - & ns & s & • \\
\hline Spain & $>$ & $>$ & $=(1)$ & $>$ & $\approx(1)$ & $\approx(4)$ & - & ns & $\cdot$ \\
\hline United Kingdom & $>$ & $>$ & $>$ & $>$ & $\geq$ & $>$ & $>$ & - & ns \\
\hline United States & $>$ & $>$ & $>$ & $>$ & $>$ & $>$ & $>$ & $>$ & - \\
\hline
\end{tabular}

Notes: Upper right triangle: $\mathrm{ns}=$ not significant. ${ }^{*}=$ significant at $5 \%,{ }^{*}=$ significant at $1 \%$. Lower left triangle: $\geq(>)=$ is (strictly) dominated by, $\approx=$ crosses at least once (number of crossings in parentheses). Thus. for example. the West German concentration curve is dominated by the Swedish and East German concentration curves and crosses the Finnish concentration curve once.

dominates that of the other, or whether the relevant concentration curves cross. ${ }^{\text {it }}$ The first two cases yield an unambiguous result, but the third does not and requires the use of the concentration index to act as a tie-breaker. These comparisons of concentration curves are made using the decile ordinates. ${ }^{\text {is }}$ Visual comparisons are not always easy, since most of the concentration curves lie close to the diagonal and the axes are scaled to run from zero to one. It is easier to compare deviations in the concentration curves from the diagonal. Examples of such comparisons are presented in Fig. 2 for four countries. The Swedish curve clearly dominates the others, whilst the U.S. curve is dominated by the other three. The Swiss and Spanish curves, by contrast, cross one another (no less than four times in fact) and cannot therefore be ranked vis-à-vis one another on the basis of concentration curves alone.

The results of the dominance-checking exercise for all pairwise comparisons are presented in the lower triangle of Table 4 . The results are more easily grasped in Fig. 3, which shows a siightly simplified version of the corresponding Hasse diagram. In Fig. 3, the concentration curves of countries on the same level intersect, whilst those of countries on different levels do not. The concentration curves of countries farther up in the diagram dominate those of countries lower down. Thus inequalities are smallest in East Germany and Sweden, whose

\footnotetext{
${ }^{14}$ The difference between dominance and strict dominance is simply that in the former case the ill-health concentration curves may coincide for some percentiles of the income distribution.

${ }^{15} \mathrm{~A}$ few recent papers in the income inequality literature (uf. Bishop et al., 1991) test for statistical difference between Lorenz curves at each decile. We could presumably devise a similar test in the context of concentration curves.
} 


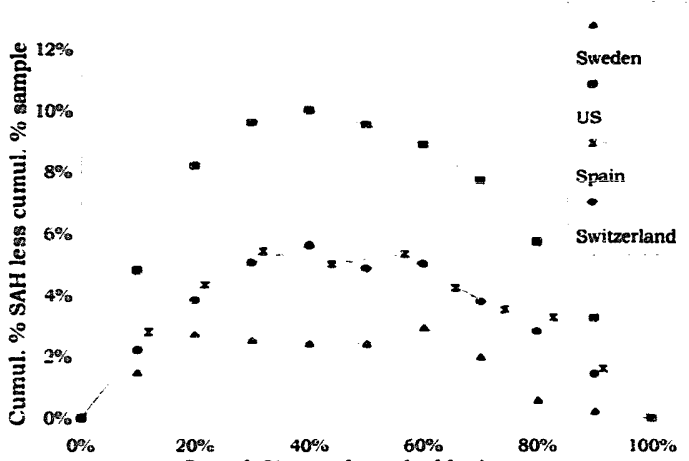

Cumul. \% sample ranked by income

Fig. 2. Concentration curves for SAH (in terms of deviations from the diagonal).

concentration curves intersect and dominate those of the group of five countries in the middle. These countries' curves in turn intersect and dominate that of the United Kingdom, whose curve in turn dominates that of the United States. The dominance-checking exercise thus gives a slightly different picture from that given by the $t$-tests. suggesting four groups of countries rather than two. Both exercises suggest, however, that inequalities in health are high in the United Kingdom and the United States, and low in East Germany, Finiand and Sweden.

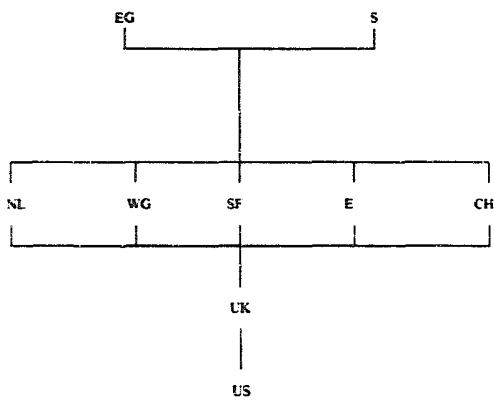

Fig. 3. Simplified Hasse diagram based on dominance of health concentration curves. Note: The diagram is inaccurate in two respects: in reality. the Swedish and Finnish concentration curves intersect. and the Spanish concentration curve lies below the West German curve. 


\section{Comparisons with previous work}

Checking the consistency of our results with those of other researchers is difficult because of the differences in variable definitions and methods used. Lahelma et al. (1994) and Lahelma and Arber (1994) compare, respectively, Finland, Norway and Sweden, and Britain and the same three Nordic countries. Both studies, however, investigate inequalities in limiting long-standing illness, rather than in self-assessed health, and neither study ranks individuals by income. ${ }^{16}$ Furthermore, although Laheima et al. measure inequality using the concentration index, Lahelma and Arber employ an approach that cannot be compared with that employed here. ${ }^{17}$ It is worth noting, nonetheless, that Lahelma et al. find a higher level of health inequality in Sweden than in Finland. This is the opposite result to that reported by Lahelma and Valkonen (1990), however, who examine differences in chronic illness across income groups. The concentration curves and indices for their results (see Wagstaff et al., 1991) show inequalities in chronic illness to be unambiguously higher in Finland than in Sweden. Lundberg (1986) and Vågerö and Lundberg (1989) compare inequalities in long-standing illness across social classes, as defined by the British Registrar General, in Britain and Sweden. The re-analysis of their results reported in Wagstaff et al. (1991) shows that the Swedish concentration curve cuts the British concentration curve from below but that the Swedish concentration index is larger in absolute value than the British index.

The only other results of which we are aware that might be compared with ours are those reported by Kunst et al. (1992, Kunst et al., 1995). They use a variant of the relative index of inequality to investigate, inter alia, inequalities in self-assessed health in various countries, including four of those included in the present study. They rank by educational and socioeconomic groups, however, rather than by income. ${ }^{18}$ When ranking by socioeconomic group, they find that inequalities in self-assessed health are a good deal higher in the Netherlands than in the United Kingdom in the case of men (though lower in the case of women), and marginally higher amongst males in the Netherlands than in Sweden. When ranking by educational attainment. they find that the United States has a higher level of inequality than Sweden, the Netherlands and the United Kingdom, but that the Netherlands has a higher level of inequality than the United Kingdom. The ranking of Sweden and the United Kingdom depends on where the cut-off point is set in the dichotomization of the seif-assessed health variable in the U.K. sample -

\footnotetext{
${ }^{16}$ Lahelma et al. stratify by educational attainment and Laheima and Arber by sociocconomic group.

${ }^{17}$ The authors regress health on socioeconomic group and tarious other variables. Notwithstanding the authors' claims to the contrary, their method does not yield a measure of seciseconomic inequality. but rather a measure of the partial effect of socioeconomic status on health, holding constant these other variables.

${ }^{18}$ They do stratify by income in their comparison of the Netherlands and Japan.
} 
if the cut-off point is set at 'fair', then the U.K.'s inequality score is higher than the Swedish score, but the opposite ranking is obtained if the cut-off point is set at 'good'. This illustrates the disadvantages of the dichotomization approach and the potential advantages of the latent variable method used in the present paper.

The picture emerging from these other studies, then, is not entirely clear - a fact that is not altogether surprising, given the different variables and methods employed. The ranking of the two Nordic countries in the present study - Finland and Sweden - is not consistent across previous studies, though the only study to date to employ income as the ranking variable obtained the same ranking as us. There is also seems disagreement in previous studies as to the ranking of Sweden and the United Xingdom, though it is worth noting that researchers who have found Sweden to have a higher level of inequality in health have been puzzled by their finding and cur opposite ranking accords better with the apparently widely held expectation that inequality generally is lower in Sweden than in the Uniter Kingdom. The only previous study to include the United States comes up with the same conclusion as we - inequalities in health there are particularly high.

\section{Sources of cross-country differences in health inequality}

Our results prompt the question: What accounts for cross-country differences in health inequality observed in our study? One obvious candidate is income inequality, the presumption being that countries with a high degree of income inequality are also those with a high degree of income-related inequality in health (cf. Blaxter, 1989; Wilkinson. 1989)). ${ }^{19}$ We might imagine that this would necessarity be the case, since we are examining income-related inequalities in health rather than pure inequalities in health. This has been argued recently by Kunst and Mackenbach (1994a) and by Kunst et al. (1995) in the context of the relative index of inequality, which is, as we noted above, closely related to the concentration index. They suggest, in effect, that a high relative index of inequality (and, by implication, a high concentration index) might be due either to a strong impact of, say, income on health, or to a high degree of income inequality. The implication is that, for a given relationship between income and health, a reduction in income inequality ought automatically to result in a reduction in health inequality, as measured by the relative index of inequality or the concentration index.

In fact, the theoretical results obtained by Lambert and Pfähler (1992) indicate that this is not the case. Let us assume that the relationship between health and income is concave. ${ }^{20}$ Consider a rank-preserving income transfer of a given sum

\footnotetext{
${ }^{19}$ The appareatly widening health inequalities in Britain are often blamed on the recent rise in income inequality (cf. Wilkinson. 1994).

${ }^{30}$ This is gusise plausible. The relationship between life expectancy and income has this shape (cf. World Bank. (1993) and it seems likely that the same is true of the relationship between morbidity and imene.
} 
from a rich person to a poor person, who have relative ranks $p_{r}$ and $p_{p}$, respectively. ${ }^{21}$ Total income is the same as before the transfer. The Lorenz curve for income is unaffected by the transfer between 0 and $p_{\mathrm{p}}$ and between $p_{\mathrm{r}}$ and 1 , but moves inwards between $p_{\mathrm{p}}$ and $p_{\mathrm{r}}$. The new Lorenz curve thus dominates the old Lorenz curve, though not strictly, and the Gini coefficient will fall. The effect on the health concentration index, by contrast, is ambiguous. Given the non-linear relationship between health and income. the increase in health of the poor person will be greater than the reduction of health of the rich person. Total health will therefore rise, though by less than the recipient's, and everyone except the recipient gets a smaller share of total health after the redistribution of income. The health concentration curve thus moves away from the diagonal up to the person just below the recipient and towards the diagonal thereafter. The new concentration curve thus intersects the old curve from below at $p_{\mathrm{p}}$ and the effect of such a transfer on the health concentration index, and hence on the relative index of inequality, is ambiguous, depending on the value of $p_{\mathrm{p}}{ }^{22}$

It is not apparently the case, therefore, that countries with a higher degree of income inequality will. other things equal, necessarily have a higher degree of inequality in health. A fortiori, we should not expect necessarily to observe a particularly close relationship between income inequality and health inequality when other things, notably average income and the relationship between health and income, are unequal. It is interesting. therefore, to find that, in our sample of countries, there is a close relationship between income inequality and health inequality. Fig. 4 shows the Gini coefficients for disposabie equivalent income ${ }^{23}$ and the health concentration indices for the nine countries in the sample. The income inequality ranking that emerges (with East Germany down at the bottom and the United States at the other extreme) is very consistent with rankings obtained from studies looking at diseributions of disposable income across households rather than individuals (cf. Atkinson et al., 1994). A fairly clear association between income inequality and health inequality emerges $(r=-0.87)$. This is consistent with the hypothesis that high income inequality generates a high degree of health inequality, though it ought to be noted that it is also consistent with the direction of causality being the opposite way. It may be, for example, that since

\footnotetext{
${ }^{11}$ A similar argument to ghat below applies if it is ill-health whose distribution is being investigated. as is the case in the empirical work reported here.

22 This result no longer holds if the rich person is the richest person and the poor is the poorest. The new Lorenz curve now strictly dominates the old, and the new concentration curve also strictly dominates the old - in this case the Gini coefficient for income and the health concentration index both fall. Lorenz dominance occurs in 21 of the 35 pairwise comparisons of the Lorenz curves for the surveys in Table 1. This may help to explain the high correlation we report below between health inequality and income inequality.

${ }_{23}$ The Gini coefficients have been calculated from decile data by means of linear interpolation.
} 


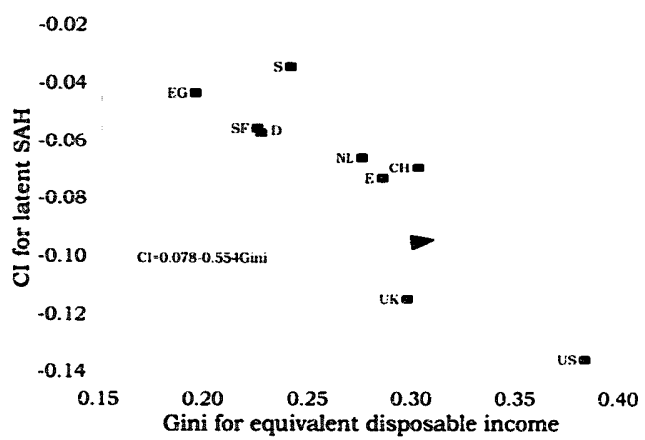

Fig. 4. Health and income inequality.

incomes (and, in particular, earnings) depend on health. a high degree of income inequality is attributable, in part at least, to a high degree of health inequality. ${ }^{24}$

Even if the causality is (primarily) from income inequality to health inequality, it is clear that differences in income inequality cannot account for the entire cross-country variation in inequalities in health. A simple linear bivariate regression of the negative of the ill-health concentration index, the Gini coefficient. for income inequality (see Table 5) yields an adjusted $R^{2}$ of only 0.71 . The regression suggests that the United Kingdom has a slightly higher level of inequality in health than one would expect on the basis of its income inequality, whilst the opposite is true for Sweden. ${ }^{5}$ The question therefore arises: What factors other than income inequality might account for the cross-country differences in health inequality? Table 5 shows the effects of adding to the simple bivariate regression of health inequality on income inequality, the variables included by Le Grand (1987) in his analysis of the sources of cross-country variation in pure health inequality. Although the sample observations in our case are clearly too few to support a serious econometric analysis, the results are nonetheless interesting. Like Le Grand, we find that per capita health care spending and the share of health expenditures financed publicly are positively associated with inequality in health, though in neither case is our coefficient significant. Unlike Le Grand, we find that per capita national income is also positively associated with heaith inequality,

\footnotetext{
27 We are grateful to a referee for this point.

25 The absolate value of the U.K.'s concentration index for the 1989 General Household Survey is marginally smaller $(-0.1047$ compared with -0.1148$)$, but leaves the U.K.'s position compared with the other countries unchanged. The U.X.'s residual is still fairly large when the additional variables discussed below are added to the equation.
} 
Table 5

Regression anaiysis of cross-country differences in health inequality

\begin{tabular}{|c|c|c|c|c|}
\hline \multirow[t]{2}{*}{ Variable } & \multicolumn{2}{|l|}{ Model 1} & \multicolumn{2}{|l|}{ Model 2} \\
\hline & Parameter & $t$-value & Parameter & $\overline{t \text {-value }}$ \\
\hline Constant & -0.078 & $(2.129)$ & -0.277 & (1.010) \\
\hline Gini coefficient for tyuivalent income & 0.554 & $(4.256)$ & 0.752 & $(2.425)$ \\
\hline GDP per capita & & & 0.002 & $(0.215)$ \\
\hline Health care expenditure per capita & & & 0.012 & (0.128) \\
\hline Public health care expenditure as a percent of total & & & 0.143 & (0.616) \\
\hline$F$-statistic for model & 18.110 & & 2.984 & \\
\hline Adjusted $R^{2}$ & 0.710 & & 0.531 & \\
\hline$F$-test of model I vs. mode: 2 & & & 0.232 & \\
\hline
\end{tabular}

Notes: Dependent variable i. negative of concentration index. Gini coefficients have been calculated from the surveys in Table $i$ wing the equivalence scales used in the analysis of inequalities in health. Other variables have been taken from OECD (1993a.OECD. 1993b) tor the year of the survey. GDP data are taken from p.34 of OECD (1993b), population data from p.11 of OECD (1993b) and heafth care expenditure data from p.108 of OECD (1993a). Per capita GDP and health expenditure have heen converted to SU.S. using PPPs of the year in question (taken from p.45 of GECD (1993b)) and have been expressed in 1985 prices using the GDP price index (taken from p.35 of OECD (1993b)). Data on the share of public health expenditure in tetal health expenditure have been taken from p.252 of OECD (1993a). East Germany has been excluded from the regression. With the exception of income inequality, the data for West Germany refer to Germany as a whole and are for 1991 not 1992.

though again our coefficient is not significant. Indeed, the coefficients of the three additional variables are jointly insignificant. It is not apparently these variables, then, that account for the portion of cross-country differences in health inequality that are left unexplained by differences in income inequality. ${ }^{26}$

\section{Summary and conclusions}

We have, we believe, achieved a high degree of comparability in our resuits. The similarities and differences that have emerged between countries ought therefore to be genuine. Our results suggest that income-related inequalities in self-assessed health exist in all nine countries and are statistically significant. In all nine countries, inequalities favour the better-off. The concentration indices vary, however, across countries, with four clusters of countries emerging: those with a relatively high level of health inequality (the United Kingdom and the United States); those with a medium level of health inequality (the Netherlands, Spain and Switzerland); those with a medium to low level of health inequality (Finland and

\footnotetext{
${ }^{26}$ Of course. given the possibility of reverse causality, we would like to explore the possibility of simulataneous equation bias in these results. We have not done so, since the sample is too small to do any serious econometric analysis.
} 
West Germany); and, finally, those with a low level of health inequality (East Germany and Sweden). Statistical tests on these index values suggest, however, that most of these differences are not statistically significant: the United States and the United Kingdom have a significantly higher degree of health inequality than the remaining countries; but amongst these latter countries, there are virtually no significant differences in health inequality. This illustrates the importance of statistical testing in health inequality comparisons.

Our results suggest that although it is not necessarily true that income-related heaith incquality ought to be closely related to income inequality, in practice this does appear to be the case - the correlation between the ill-health concentration index and the Gini coefficient for disposable equivalent income in our sample of countries is -0.87 . The correlation is, however, not perfect and Sweden and the United Kingdom are interesting outliers, with Sweden having less health inequality than would be expected given its income inequality, and the opposite being true of the United Kingdom. We explored additional factors which, on the basis of previous research. might be expected to explain at least some of the variation in health inequality left unexplained by income inequality, but these variables were jointly insignificant in a regression explaining cross-country differences in health inequality. Quite what influences a country's degree of health inequality, other than income inequality, and what, in particular, causes the United Kingdom to have a higher degree of health inequality than one would expect given its income inequality, are puzzles we leave for future research.

\section{Acknowledgements}

This paper derives from the project 'Equity in the Finance and Delivery of Health Care in Europe' (known as the ECuity Project), which is funded in part by the European Community's Biomed I programme (contract BMH1-CT92-608). We are grateful to the EC for financial support. We are also grateful to the other participants in the ECuity Project and to Nanak Kakwani and Peter Lambert for their contributions to the research leading up to this paper and to Anton Kunst for helpful comments on an earlier version of the paper. We alone are responsible for any errors.

\section{References}

Atkinson. A.B., 1970. On the measurement of inequality. Journal of Economic Theory 2. 244-263.

Atkinsors, A.B.. L.. Rainwater and T. Smeeding. 1994. Income distribution in European countries, Mimeo. Luxembourg Income Study. Luxembourg.

Bistop. J.A.. I.P. Formby and W.J. Smith. 1991. International comparisons of income inequality: Tests for Lorenz dominance across nine countries. Esonomica 58, 46i-477. 
Blaxter. M.. 1989. A comparison of measures of inequality in morbidity, in: J. Fox, ed., Health inequality in European countries (Gower, Aldershot).

Hisley, R. and J. Le Grand, 1987, The measurement of inequalities in heaith, in: A. Williams, ed., Heatth and economics (Macmillan. London).

Kakwani, N.C.. 1977, Measurement of tax progressivity: An international comparison. Economic Joumal 87, 71-80.

Kakwani, N.C., 1980. Income inequality and poverty: Methods of estimation and policy application (Oxford University Press, New York).

Kakwani, N.C., A. Wagstaff and E. van Doorlsaer. 1997, Socioeconomic inequalities in health: Measurement, computation and statistical inference, Journal of Econometrics, forthcoming.

Koskinen, S., 1985, Time-trends in cause-specific mortality by occupational class in England and Waies, Paper presented at IUSSP 20 h General Conference, Florence.

Kunst, A.E., J. Geurts and J. van den Berg, 1992, International variation in socioeconomic inequalities in self-reported health (Dutch Central Bureau of Statistics, Voorburg).

Kunst, A.E., J. Geurts and J. van den Berg, 1995, International variation in socioeconomic inequalities in self-reported health. Journal of Epidemiology and Community Health, in press.

Kunst, A.E. and J.P. Mackenbach, 1992, An intemational comparison of socioeconomic inequalities in montality. Report MGZ 92.11. Department of Public Health and Social Medicine. Erasmus University, the Netherlands.

Kuns:, A.E. and J.P. Mackenbach, 1994a, Size of mortality differences associated with educational level in nine industrialized countries. American Joumal of Public Health 84, 932-937.

Kunst, A.E. and J.P. Mackenbach, 1994b, Measuring socioeconomic inequalities in health (World Health Organization, Regional Office for Europe, Copenhagen).

Laheima. E. and S. Arber, 1994. Health inequalities among men and women in contrasting welfare staies, European Journal of Public Health 4, 213-226.

Lahelma, E. K. Manderbacka, O. Rahkonen and A. Karisfo, 1994, Comparisons of inequalities in health: Evidence from national surveys in Finland, Norway and Sweden, Social Science and Medicine 38, 517-524.

Lahelma, E. and T. Vaikonen. 1990, Health and social inequities in Finland and elsewhere, Social Science and Medicine 3!, 257-265.

Lambert. P.J., 1993. The distribution and redistribution of income: A mathematical analysis (Manchester University Press, Manchester).

Lambert. P.J. and W. Pfahler, 1992. Income tax progression and redistributive effect: The influence of changes in the pre-tax income distribution. Public Finance 47, 1-16.

Le Grand. J., 1987, Inequality in health: Some intemational comparisons, European Economic Review 31, 182-191.

Le Grand. J., 1989, An international comparison of distributions of ages-at-death. in: J. Fox, ed., Health inequality in European countries (Gower, Aldershot).

Le Grand. J. and M. Rabin, 1986. Trends in British health inequality: 1931-83, in: A.J. Culyer and B. Jönsson. eds.. Public and private health services (Blackwell, Oxford).

Lundberg, O., 1986. Class and health: Conparing Britain and Sweden. Social Science and Medicine 23. $511-517$.

OECD, 1993a, OECD health systems, Voi. I: Facts and trends 1960-1991 (OECD, Paris).

OECD, 1993b, OECD health systems, Vol. Il: The socio-economic environment statistical references (OECD, Paris).

O'Higgins, M.. G. Schmaus and G. Stephenson, 1990. Income distribution and redistribution: A microdata analysis for seven countries. in: T. Smeeding. M. O'Higgins and L. Rainwater. eds., Poverty, inequality and income distribution in perspective: The Luxembourg income study (Harvester. Brighton).

Pamuk E., 1985. Social class inequality in mortality from 1921 to 1972 in England and Wales. Population Studies 39, 17-31. 
Pamuk E.. 1988. Social-class inequality in infant mortality in England and Wales from 1921 to 1980 , European Joural of Popsiation 4, 1-21.

Pappas, G., S. Queen, W. Hadden and G. Fisher, 1993, The increasing disparity in monality between socioecunomic groups in the United States. 1960 and 1986. New England Joumal of Medicine 329. ถo. 2. 103-109.

Preston S.H., M.R. Haines and E. Pamuk. 1981. Effects of industrialization and urbanization on arortality in developed cusanties, in: Sulicited papers, Vol. 2. IUSSP 19th Intemational Population Conference (IUSSP. Liege).

Vågerö. D. and O. Lundberg. 1989, Health inequalities in Britain and Sweden. The Lancet ii, 35-36.

Valkonew. T., 1989. Adutr mortality and the level of education, in: J. Fox, ed.. Health inequality in Europeas countries (Gower, Aldershot).

van Doorslaer. E. A. Wagstaff and F. Runten. eds.. 1993. Equity in the finance and delivery of health care: An international perspective (Oxford University Press. Oxford).

Wagsiaff. A. and E. van Dourslaer. 1993. Equity in the delivery of health care: Methods and findings. in. E. van Doorslaer. A. Wagstaft and F. Rutten, eds.. Equity in the finance and delivery of health care: An international perspective (Oxforu University Press, Oxford).

Wagstaff. A. and E. van Doorslaer, 1994, Measuring inequalities in health in the presence of multiple-category morbidity indicators. Health Economics 3. 281-291.

Wagstaff A.. E. van Doorslaer and P. Paci, 1989. Equity in the finance and delivery of health care: Some tentative cross-cuuntry comparisons, Oxford Review of Economic Policy 5, 89-112.

Wagstaff, A.. P. Paci and E. van Doorslaer. 1991. On the measurement of inequalities in health. Social Science and Mediciane 33. 545-557.

Wilkinson, R., 1989, Class mortality differentials, income distribution and trends in poveny. Journal of Social Poticy 18, 307-335.

Wilkinson, R. 1994, Divided we fall. British Medical Journal 308, 113-114.

World Bank. 1993. World development report 1993: Investing in health (World Bank, Washington. DC). 